\title{
Accelerating debate
}

Sea-level research, like hardly any other topic, confronts geoscientists with the needs of society. Some 146 million people live in locations that are less than one metre above sea level. And hundreds of billions of euros or dollars are at stake: climate researchers' forecasts for sea-level rise determine how much tax money needs to be spent on coastal protection. The Intergovernmental Panel on Climate Change (IPCC) has commissioned a group of 18 select scientists from 10 countries to decide which prognoses will be considered in the next United Nations (UN) climate report. Hundreds of studies are under discussion.

In 2007, the latest IPCC report predicted sea-level rise of up to $59 \mathrm{~cm}$ by the end of the century - plus a potential contribution

\section{The journalist's take}

Climate research is a difficult subject for a journalist. Relevant articles are usually read by only a relatively small audience, yet they tend to generate vigorous debate. At Spiegel Online, we receive hundreds of letters for every climate change article published.

And the difficulties don't end there. On some key questions, such as future sea-level rise, the scientists just do not know the answer. The worried public expects reliable prognoses nevertheless. The politicization of climate change does not help either. Open public debate of new research is often seriously hampered: for fear of being pigeonholed as 'sceptics' or 'alarmists', journalists as much as scientists often do not air their criticisms. But of course, asking critical questions is not a sign of malice. From a reporter's point of view, it is essential to challenge what you hear: it marks the boundary between advertising and journalism.

Despite these drawbacks, we made the sea-level debate our opening story during prime time, because it features:

- Relevance: sea-level rise is directly important to many people, not only for coast dwellers but also for everyone whose taxes will be spent on coastal protection.

- Bad news makes 'good' news: people want know when danger is looming.

- Status: the UN, the world's most senior international organization, addresses the question. of unknown magnitude from poorly understood ice dynamics in Greenland and Antarctica. Since then, researchers have published alarming sea-level projections that far exceed the range of the 2007 report (for example, Geophys. Res. Lett. 37, L07703; 2010). However, actual measurements of sea level do not back up these projections. So far, scientists have neither observed an extreme rise nor reached a consensus on the question of whether sea level has been going up more quickly in recent years. There is only one certainty: in global average terms, the water is rising.

Until 1993, the data were based only on readings from in situ tide gauges. Since 1993, satellites have also been used to measure the oceans. These have registered a rise of as much as three millimetres per year. Some studies see a recent acceleration in the rise in sea level (for example, J. Climate 22, 5772-5781; 2009). But deciding what constitutes an acceleration is not so simple, as John Church of Australia's Commonwealth Scientific and Industrial Research Organisation and head of the IPCC Sea Level Working Group points out: "The rate of rise has increased from the nineteenth to the twentieth century and during the twentieth century." The rate of rise in recent years is larger than the twentieth century average, but whether or not this is a further acceleration is not yet clear, says Church. Eduardo Zorita of the GKSS Institute of Coastal Research confirms: "I would say that the data quality does not allow for asserting an acceleration or deceleration." The rate of sea-level rise has slightly decreased in the last eight years, says Zorita. According to Simon Holgate, a sea-level researcher at the National Oceanography Centre in Liverpool, the rise over the past 20 years is nothing unusual in comparison to other decades of the twentieth century (Geophys. Res. Lett. 34, L01602; 2007). This state of affairs is puzzling. Melt rates in Greenland and Antarctica have been reported to be going up (Geophys. Res. Lett. 38, L05503; 2011), and faster melt should speed up the rise in sea level.

The future is no clearer. The UN climate report of 2007 emphasized that the dynamics of the ice masses in Greenland and Antarctica were poorly understood, and had to exclude an assessment of possible future ice-sheet melt. But since then, there have been hints that the water levels will be going up faster in coming decades. A scientist from the Technical University of Delft in the Netherlands, Riccardo Riva, says: "More evidence has been collected in the past

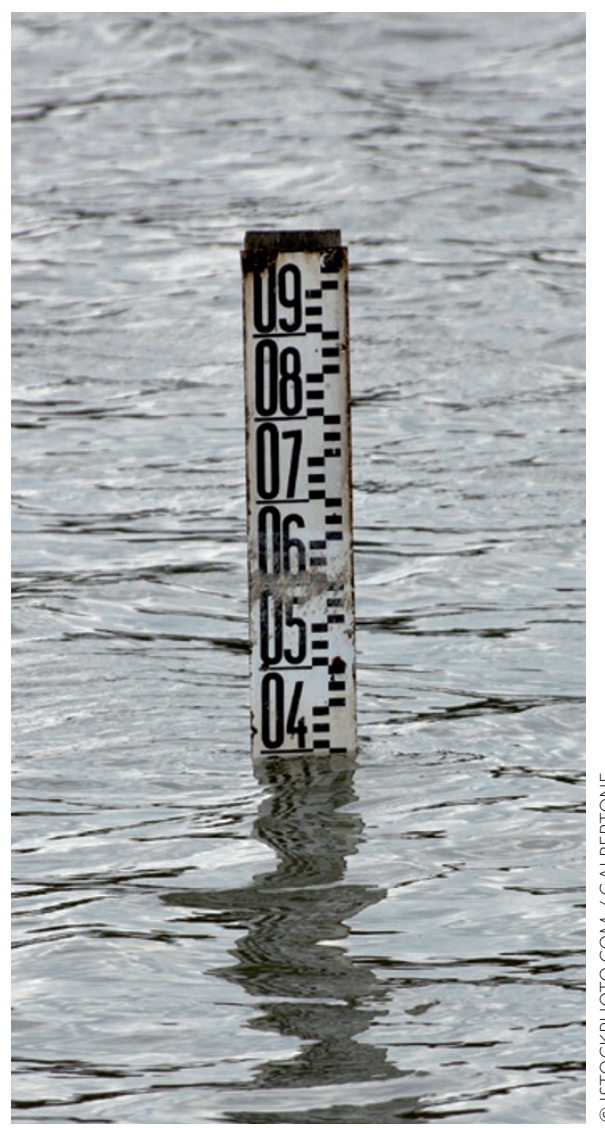

decade showing that an acceleration could in fact take place."

Data from earlier warm periods do not bring comfort (Nature 458, 881-884; 2009). Tropical reefs that are six metres above the surface of the sea at present must have been in the water 125,000 years ago - at a time when it was as warm as projected for later this century. But it is less clear how rapidly sea level can rise. Without a speed-up, global sea level would rise by only $27 \mathrm{~cm}$ by the year 2100 . In the highest claim yet by a long way, NASA climate researcher James Hansen foresees sea level going up five metres by the same date. In stark contrast, his colleague Simon Holgate says, "I think that even in the highest emission scenario we won't exceed a global average of one metre of sea level rise by 2100 ."

Undoubtedly, the 18 members of the IPCC Sea Level Working Group, commissioned to provide a fair overview of these divergent estimates, are facing a challenge.

Axel Bojanowski covers the Earth sciences for Spiegel Online, the top German-language news portal. 